Western University

Scholarship@Western

Geography Publications

Geography Department

2010

Linking Health Inequality and Environmental Justice: Articulating a Precautionary Framework for Research and Action

Sarah Wakefield

University of Toronto

Jamie Baxter

University of Western Ontario

Follow this and additional works at: https://ir.lib.uwo.ca/geographypub

Part of the Geography Commons

Citation of this paper:

Wakefield, Sarah and Baxter, Jamie, "Linking Health Inequality and Environmental Justice: Articulating a Precautionary Framework for Research and Action" (2010). Geography Publications. 272.

https://ir.lib.uwo.ca/geographypub/272 


\title{
Linking Health Inequality and Environmental Justice: Articulating a Precautionary Framework for Research and Action
}

\author{
Sarah E.L. Wakefield and Jamie Baxter
}

\begin{abstract}
This article draws together three issues—-the environment, health, and (in)justice-with the overall purpose of articulating an agenda for policy and research that works towards improved justice and sustainability in the environmental health arena. Considerable research in the United States and elsewhere has shown that both environmental exposures and poor health are more prevalent in populations that are marginalized by race and social class (typically measured as income). The logical next step has been to attempt to establish concrete cause-effect links between health effects and environmental exposures in order to mobilize government action to reduce these disparities. However, we caution against pursuing such causal links alone as a necessary precondition for just and sustainable environmental health policy. We instead argue for a framework that considers both environmental justice and health inequality in terms of compounded disadvantage at the community level. We support a precautionary approach to action that simultaneously pays due attention to the processes leading to injustices/inequities as well as remediating current patterns of injustice/inequity.
\end{abstract}

\section{INTRODUCTION}

E NVIRONMENTAL JUSTICE has become such a potentially vast area of action and research enquiry that it is worthwhile to highlight powerful conceptual and theoretical linkages that already do and should continue to guide such work. Yet we are concerned about an overemphasis in certain areas-particularly cause-effect linkages between environment and health-to the expense of other areas of enquiry and action. Though physical health may not be linked to disproportionate environmental degradation, the latter is often still worthy of corrective action and prevention.

Identifying and mitigating the negative environmental effects of development has been a focus of research and

Dr. Wakefield is Associate Professor, Department of Geography, at the University of Toronto. Dr. Baxter is Associate Professor, Department of Geography, at the University of Western Ontario in London, Ontario. activism since the beginning of the industrial era. The intensity of environmental exploitation has increased dramatically in the last two and a half centuries, with concomitant effects on ecosystem and human health. For example, the Canadian Medical Association estimates 21,000 Canadians will die from air pollution in 2008 alone. ${ }^{1}$ In this article, we are concerned primarily with the distribution of such impacts over space and particularly among different social groups and the processes that generate such distributions. We recognize that environmental exploitation (e.g., the extraction and use of renewable and non-renewable resources and the release of pollutants into the air, water, and soil) can generate economic and social benefits, but they often also generate risks to health and quality of life. Our interest is in better understanding how to interpret the differential burden of health and environmental risks borne by certain groups in society, groups that often do not share equally in the economic and social benefits generated by environmental exploitation. Though readers of this journal are no strangers to understanding this lack of proportionality 
through the lens of environmental (in)justice or (in)equity, ${ }^{*}$ we are concerned that the gaze remains holistic.

Though we are using the terms justice and equity interchangeably here they are rooted in Rawls' broader ideas about social justice that deny using "for the greater good" as legitimating disproportionately poor health and environments for the marginalized and/or disadvantaged. ${ }^{2}$ Indeed environmental justice may be considered a particular case of social justice where physical environmental degradation (e.g., hazardous facilities, chemical contamination, air pollution) and increasingly, social environmental arrangements (e.g., housing, transportation, urban design) are involved. Yet, definitions of environmental justice often include health specifically. For example Bullard ${ }^{3}$ defines environmental justice as something very fundamental as, "embracing the principle that all people and communities are entitled to equal protection of environmental and public health laws and regulations" (493). Yet this assumes that legal frameworks are in place to guide such protection-which is often not the case, particularly outside the U.S.

This article draws together three main bodies of theory and research: environmental justice, health inequalities, and environment and health. We highlight connections between these literatures for the purpose of reinforcing an agenda for research into environmental inequity that is theoretically and methodologically robust, and which can be used in a variety of national and international contexts to interrogate the impact of socioeconomic structures, government policies, and institutions in mitigating or reinforcing inequities. The agenda we propose is not entirely new, but we highlight and pull together some threads developing in the literature to encourage future work in these areas. One avenue for studying environmental justice is to conduct studies which show the coincidence of high pollution exposure, poor health, and socioeconomic disadvantage. The hypothesis is that pollution causes negative physical health effects and the pollution itself is located disproportionately in places of high socioeconomic disadvantage. In effect, pollution inequity is identified as a key cause of health inequality alongside well-known findings concerning health inequalities from other aspects of socioeconomic status ${ }^{4}$ (see Figure 1). Our basic position in this article is to caution against prioritizing the establishment of causal links be-

*A note on terminology: Environmental justice is the term often used to refer to the movement that seeks to reduce the disproportionate environmental impacts on marginalized communities, particularly communities of color. Cutter (1995) suggests studies of environmental equity have been more open to investigating other axes of difference beyond race (social class, gender, etc.), but also less likely to emphasize the root causes of inequity (e.g. colonialism and structural racism). The use of "environmental equity" is thus politically charged for some, in that it may signal a denial of presumed root causes. However, the term "equity" is often used outside of the U.S. and in the health literature. In this article, we use both terms relatively interchangeably, tending to use "inequity" to describe existing conditions and the research that describes them, and "justice" to describe both the ideal and the movement that works towards it. tween environmental inequity and health inequalities as the primary means of addressing inequalities in either or both realms-especially if this excludes other meaningful avenues of enquiry. Though we are certain pollution, poor health, and social disadvantage coincide in time and space, we are concerned that the search for places with such explicit causal associations will be frustrated by the limitations of research design and data availability in the here and now. That is, the affected communities will suffer from a scientific approach that is by design conservative, cautionary, and thus prone to false negative findings. ${ }^{5}$ It is difficult enough to show that exposure to environmental pollution causes negative health outcomes, and that difficulty is compounded if one wants to further show that that pollution exposure is an underlying cause of health inequality. One approach is to exercise the precautionary principle when interpreting the results of such studies, since it is very difficult for the victims of environmental injustice to rail against scientific findings, particularly if they are published in ostensibly neutral scientific journals. ${ }^{6}$ A second is to adopt a more holistic view of these problems.

Though such "causal" research should indeed continue, we are nevertheless concerned that other meaningful efforts to research environmental inequity and health inequality continue-e.g., ethnographic and other case studies, research informed by critical theory, legal analyses, and political ecological research. ${ }^{7}$ In this article, we lay out a simple framework for understanding environmental injustice as compounded disadvantage (Figure 2), rather than as the somewhat linear and limiting single exposure linked to a single physical health outcome as depicted in Figure 1. That is, overall we must not lose sight of a more holistic and community-focused model, whereby inequities in both health and environments are problems in their own right and need not be causally linked as a basis for action.

In order to expand on this position we briefly review the how the connections between environment and health have traditionally been understood by environmental justice and health researchers. We then elaborate a new, broader, conceptual framework for understanding environmental inequity and health, and discuss the implications of this latter framework for research that could serve to bridge the gaps that currently exist between environmental justice, health inequalities, and environment and health research.

\section{EQUITY, HEALTH, AND THE ENVIRONMENTAL JUSTICE MOVEMENT}

Although environmental concerns have been related to justice issues from at least the early industrial era, ${ }^{8}$ most observers tie the rise of environmental justice, as both a concept and a stream within the environmental movement, to the environmental activism of communities of color in the United States at the end of the twentieth century. Protests by poor black residents brought attention to the disproportionate siting of noxious facilities in communities of color, ${ }^{9}$ an assertion that was empirically 


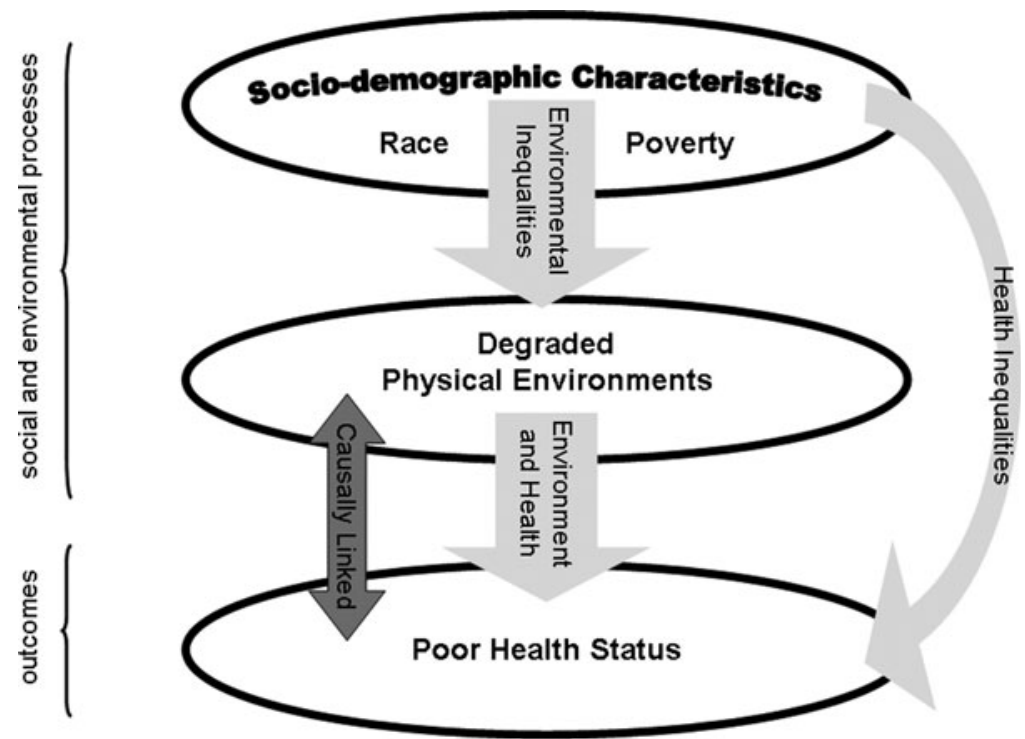

FIG. 1. Common view of the relationships between individual/community characteristics such as race and poverty, the physical environment, and health. In this model, there are two paths to reduced health status: (1) the degradation of the physical environment; and (2) socio-demographic characteristics themselves. A lack of causal linkage could (incorrectly) be used to support inaction.

verified in a later United Church of Christ report and confirmed in a follow-up report 20 years later. ${ }^{10,11}$ As Palamar $^{12}$ notes, certain communities are often targeted for potentially hazardous facilities that are unwanted elsewhere:

companies and localities seeking sites for garbage dumps and incinerators will find the least resistance from small (under 25,000 people), rural, poor, under-educated, minority communities whose jobs are primarily located in resource extraction and development industries (such as mining, agriculture, or timber). In other words, they would find the least resistance from (and be most successful in locating in) poor, minority communities... Quite simply, some groups are paying a much higher price for industrial development than others. (88)

Subsequent research has identified that low-income and minority populations are disproportionately exposed to a wide range of potential or actual environmental

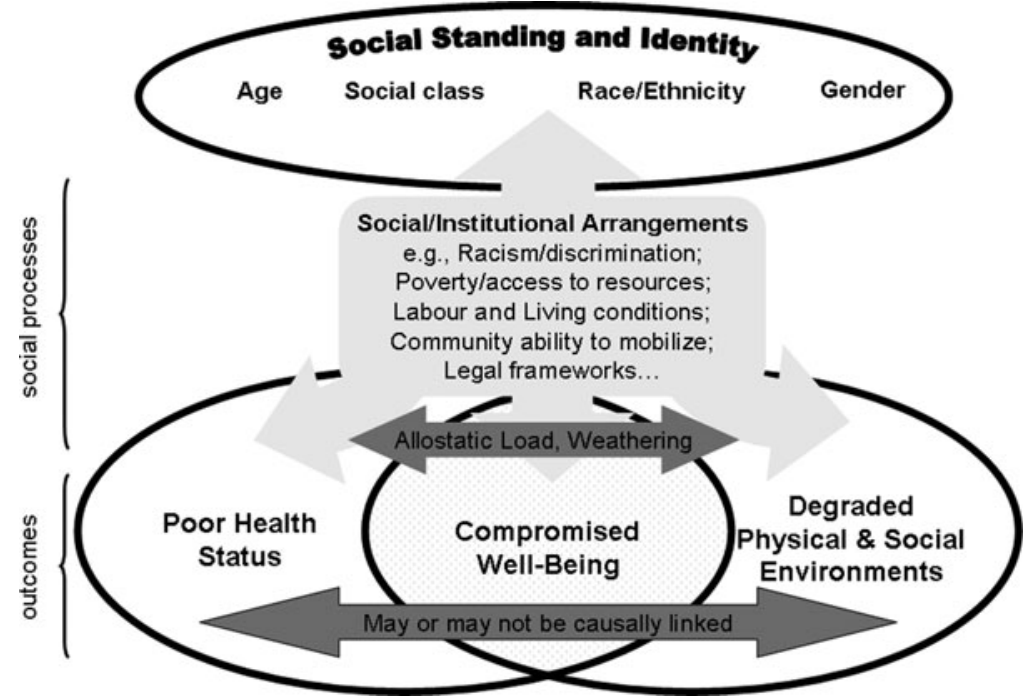

FIG. 2. Compounded disadvantage and its impacts on well-being. This figure shows how social standing, acting through a myriad of intervening social structures and processes, impacts on physical environments and health status to have additive or multiplicative impacts on overall well-being. Poor health status need not be causally linked to degraded physical environments because they are both impacts in their own right. The ongoing processes that support injustice as well as existing outcomes require action for positive change. 
contaminants, including waste facilities and other noxious land uses, ${ }^{7,13}$ soil lead, ${ }^{14}$ and poor air quality. ${ }^{15,16}$

These findings have served to mobilize a new form of environmental activism, organized around the pursuit of environmental justice. This movement, particularly in the United States, has emphasized the fight against environmental racism-that is, policies and practices that place facilities and pollution more frequently in the vicinity of people of color. ${ }^{17}$ Outside the United States, more limited attention has been paid to environmental justice. In the United Kingdom, Europe, and Canada, a few recent articles point to a rising interest amongst academics, ${ }^{18,19,20}$ but the issue has received considerably less emphasis among activists than in the United States.

Some of the core environmental justice writers, though concerned with exposure, ${ }^{21}$ are also advocating for more studies to show direct, causal linkages between poor environments and poor physical health (disease)-e.g., Bullard and Wright. ${ }^{22}$ Indeed, there is a tacit assumption that pollution exposure affects health in much of the environmental justice literature, but what is troubling is that the assumption of such linkages is often used to create doubt about the necessity for action by polluting industries and governments. For example, in a scathing methodological review of landmark environmental justice/ equity studies, Bowen ${ }^{23}$ suggests that: "... little to none of the research is meaningfully linked to actual exposure and associated public health effects" (10). This suggests that inequalities in the distribution of environmental exposures and risks are only a concern when a causal link to poor health can be demonstrated. We find this ethically unpalatable, since exposure to polluting facilities is an annoyance that may decrease quality of life (well-being) for example through dust, odor, and reduced quality of local water bodies. Further, persistent concern about possible health risk is a psychosocial impact ${ }^{24,25}$ that should be seen as injustice in its own right. Thus, environmental justice and equity researchers need to be cautious about what may be gained by focusing on both expecting to determine causal links between environmental degradation and health and measuring health as disease alone (as opposed to a more holistic view of health).

\section{EQUITY AND THE ENVIRONMENT IN HEALTH RESEARCH}

In the last few decades, there has been a resurgence of interest in public and preventative health. ${ }^{26}$ Initially, this resurgence was focused on the impact of lifestyle change (e.g., the role of nutrition and exercise) on individual health, but it has now broadened to include interest in health equity, particularly in relation to the economic and social determinants of health. ${ }^{27,28,29}$ Within this literature, health is viewed holistically, as "a state of complete physical, mental and social well-being and not merely the absence of disease or infirmity". ${ }^{30}$ This is typically contrasted to a narrow bio-medical definition of health, which focuses exclusively on the physical manifestations of disease. ${ }^{23}$
Recent literature on the social determinants of health ${ }^{31,32,33}$ focuses on the relatively poor health experienced by marginalized populations, including the poor and racialized groups. Research in this area has identified the so-called health gradient, whereby each successively lower level of socioeconomic status is accompanied by proportional declines in health status. ${ }^{34}$ In the United States, some of this literature has examined the connection between race and health. ${ }^{35,36,37}$

In health research, there seems to be a greater comfort with making strong claims about the injustice imbedded in inequalities in health. That is, differences in health-at least, those not caused by individual behaviors such as smoking or diet-are seen as fundamentally unjust. $^{38}$ Reducing the systematic disparities in health between groups with different social advantages/disadvantages has become a goal of public health policy development and health service delivery in several jurisdictions. ${ }^{39}$ By contrast, in much of the literature that specifically links health and the environment, studies about equity/justice are still relatively rare (but growing).$^{40,41}$ Environment and health research which does address environmental justice can retain the narrow "single environmental cause to single disease impact" perspective (the doctrine of specific etiology) that is prevalent within the biomedical approach. ${ }^{42}$ For example, Landrigan et al. ${ }^{43}$ urge that, "documentation of linkages between health disparities and environmental injustice is an important step toward achieving environmental justice." Indeed environmental and public health activists put health front and center in the environmental justice movement. ${ }^{44}$ We wholeheartedly agree, as long as it is not the only step and that absence of such linkages is not used as an excuse for inaction regarding either poor health outcomes or degraded physical environments (see Figure 2). There is increasing articulation in this literature of a more holistic view of how environmental exposures affect vulnerable individuals and communities. ${ }^{45}$ For example, Lee $^{46}$ refers to broad sets of health outcomes, as well-being, including "stressors" and "psychosocial" health more generally, and that these connected to a broad set of exposures not single ones. However, a broader perspective such as this is still relatively rare in this literature-in general, the focus thus far has been on assessing the physiological health effects of environmental contamination in particular localities, using quantitative methodologies derived from epidemiology, toxicology, disease ecology, and risk assessment. ${ }^{47}$

Figure 1 represents a common view of how health inequities, and environmental justice may be connected through causal linkages between degraded environments and poor health outcomes. ${ }^{48}$ There are some encouraging examples of how communities can organize to see that environment and health studies are done, and corrective actions are taken. ${ }^{49,50,51}$ Unfortunately, our understanding of the specific connections between environment and health is limited by the tools available for linking exposure and disease. We are now able to identify and monitor the presence of toxins in the environment, and have developed various techniques (from laboratory methods to statistics) to understand their effects. Though the 
associated toxicological and epidemiological techniques are potentially powerful, resources are typically scarce for governments, and particularly for affected communities who are often already impoverished. Thus, it remains extremely difficult in many cases to trace specific human disease impacts to particular contaminants in real world situations. For example, the doctrine of specific etiology is of limited value when dealing with real-world complexity (for example, in relation to cancer causation outside the toxicologist's laboratory). Add to this epidemiologic study design limitations, modifiable areal unit problems, small number problems, and issues with lag time ${ }^{52,53}$ a plethora of issues present challenges for doing traditional causeeffect environment and health research in community settings. Though exposures may be demonstrable (top of Figure 1), linking various health impacts directly to those exposures may remain murky (bottom of Figure 1) despite continued advances in environment and health research. Two related limitations of environment and health research are (1) the so-called upstream determinants, or social causes, of exposures are often poorly explored and not considered reasonable points of intervention, and; (2) health is narrowly defined as disease rather than overall well-being-the latter being tacitly linked to environmental degradation broadly speaking.

\section{DISCUSSION: A FRAMEWORK FOR UNDERSTANDING ENVIRONMENTAL INJUSTICE}

As described in the previous section, proving connections between environmental exposures and health outcomes is fraught with difficulties even for the wellresourced. At the same time, the rise of environmental justice as a mobilizing concern for marginalized communities suggests the need for a framework that can better capture the potential impacts of disproportionate exposure to contaminants on well-being. In addition, a framework is needed that makes sense in relation to a broader understanding of equity than is provided by environmental racism in the U.S. context, providing a more general and holistic approach to the environment-equity/ justice-health nexus. With these issues in mind, we propose the heuristic outlined in Figure 2. Rather than emphasizing the causal connections between environmental exposures and health outcomes (as seen in Figure 1), this framework instead focuses on compounded disadvantage and its threat to well-being. Sometimes referred to as "multiple vulnerabilities" in the health literature, ${ }^{54}$ compounded disadvantage can be defined as the cumulative hardship experienced by marginalized populations as a result of multiple and overlapping challenges to wellbeing and autonomy. The challenges faced by marginalized populations can include what are labeled at the bottom of Figure 2 as "outcomes," direct insults to health, degraded environments, or both. Further, certain groups may even be more susceptible to genetic damage that is compounded by social disadvantage. ${ }^{55}$ Yet it is important to recognize that these outcomes are each embedded in, or determined by, social processes and structures like the ones listed in the middle of the Figure 2. For example, racism and discrimination have been found to increase blood pressure, ${ }^{56}$ reduce mental health, ${ }^{57,58}$ and increase maladaptive coping strategies such as excessive alcohol consumption. ${ }^{59}$ At the same time, structural (and occasionally overt) racism has been observed in the siting of noxious facilities, as described earlier. Similarly, inadequate access to resources (i.e., poverty) can have both material and psychosocial effects on health, ${ }^{60}$ and at the same time limits the communities in which a person can afford to live. Thus, the likelihood of exposure to degraded environments may increase, for example, through adjacent contemporary or historical noxious land uses or as a result of deteriorating housing. The arrow points from such processes back to "social standing and identity" in the figure since these process and structures may reproduce communities (identities) that continue to feel powerless to affect change. Thus, many of the challenges faced by marginalized communities can impact on health and the environment independently, without a necessary causal relationship between the two-it is the institutionalized social processes that (re)produce both such outcomes that deserve to be at center stage.

Rather than emphasize only causal linkages between poor health and poor environments, this heuristic also builds on conceptions in the literature that stress the cumulative effects of marginalization. For example, Geronimous ${ }^{61,62}$ outlines the "weathering hypothesis," suggesting that health deteriorates at an increased rate over time as a consequence of the cumulative impact of repeated experience with social or economic adversity and political marginalization. ${ }^{63}$ In addition to the direct effects of marginalization, the various coping strategies used to deal with - or challenge- these structural barriers exact their own health costs. ${ }^{64,65,66}$ MacEwen $^{67}$ and others link this differential impact to the biophysical mechanisms of the stress response through the concept of allostatic load-the cumulative wear and tear on the body's systems that results from the constant stress and repeated adaptation to stressors experienced by marginalized individuals. ${ }^{68}$

The continuous activation of the stress response experienced by the marginalized is hypothesized to increase susceptibility to environmental contaminants as well. ${ }^{69}$ Building on the work of Sexton, ${ }^{70}$ Gee and PayneSturges $^{71}$ posit that disadvantaged populations are more vulnerable to the effects of environmental hazards because the greater stress they experience could compromise immune resistance, enhancing vulnerability. They suggest that community and/or neighborhood conditions such as the vibrancy of the local economy, the condition of housing and infrastructure, the amount of crime, and the level of community organization can reduce or increase stress, and that this stress is mediated-either reduced or compounded-by individual stressors such as access to resources. ${ }^{54}$ Stress, in turn, is thought to increase vulnerability to environmental toxins, at the same time as it increases the risk of other adverse health outcomes, such as heart disease. ${ }^{72}$

Importantly though, the nature of the environmenthealth connection is not the focus of the model in Figure 2. 
Instead, the model emphasizes the constant and at times overlapping challenges experienced by the marginalized, and the consequent cumulative effects on well-being and back to individual and community identity. Approaching environmental justice investigations with this in mind would move the focus from proving environment-health links to assessing more holistically the types of health challenges faced by a particular community. By establishing the coincidence of poor environmental conditions, poverty, experience of racism, limited community "say" in local development/underdevelopment, and other factors that negatively influence health, a "total community burden" could be determined. In instances where the total community burden is high, it would be reasonable to assume that an unjust situation exists and the precautionary principle should be invoked. Using this approach, environmental injustice "hotspots" could be identified for intervention, and a clearer picture of the nature of compound disadvantage-one that takes into account the diversity of issues that affect marginalized populations, not just race and/or income-could be developed. The proposed framework takes the focus off the specific etiology of the poor health experienced by disadvantaged communities, and refocuses attention on the multiple, layered, and interacting experiences of disadvantage in those communities. By doing so, the door is opened for a wider range of approaches to the study of environmental justice, incorporating, for example, both qualitative and quantitative methods and integrated, interdisciplinary approaches to research and policy.

\section{CONCLUSION}

In this article, we outline the key facets of three discrete but overlapping bodies of literature-environmental justice/equity, inequalities in health, and environment and health. Building on the strengths and limitations within these literatures, and the need for a more holistic conception of the environment-equity-health nexus, we articulate a framework for understanding connections that are already developing in all three of these areas. We highlight the concept of compounded disadvantage as a way of understanding the multiple and overlapping health challenges faced by marginalized communities, and suggest that identifying environmental inequities need not be tied to proving a causal relationship between a specific environmental contaminant and a specific disease outcome. Thus, we advocate a precautionary approach for taking action on both the processes that produce environmental injustice and health inequalities and existing patterns of injustice which may be related to exposure alone. While the framework outlined here has the potential to move environmental equity research forward, on its own it does little to advance environmental justice. As Gee and Payne-Sturgess ${ }^{73}$ note, "reduction of the gap in health between advantaged and disadvantaged groups... may require interventions targeted at eliminating the gap in advantages themselves" (1650). Similarly, facilitating environmental equity may require a fundamental re-thinking of the socioeconomic and regulatory structures that lead to inequity and hence injustice. We agree with Masuda et al. ${ }^{74}$ who suggest that "addressing the disproportionate environmental burden experienced by vulnerable populations requires a deepened understanding and critique of complex power relations built into systems of environmental governance." Without tackling these broader issues, frameworks for understanding equity-such as the one outlined above-will have little impact on the day-to-day lives of marginalized communities.

\section{AUTHOR DISCLOSURE STATEMENT}

The authors have no conflicts of interest or financial ties to disclose.

\section{REFERENCES}

1. Canadian Medical Association. No Breathing Room: National Illness Costs of Air Pollution. (Ottawa: Canadian Medical Association, 2008).

2. J. Rawls. A Theory of Justice. (Cambridge, Massachusetts: Belknap/Harvard University Press, 1971).

3. Robert. D. Bullard, "Environmental justice: It's more than just waste facility siting," Social Science Quarterly 77 (1996): 493-99.

4. Nancy E. Adler and Katherine Newman, "Socioeconomic Disparities in Health: Pathways and Policies," Health Affairs 21 (2002): 60-76.

5. Gary Taubes and Charles C. Mann, "Epidemiology faces its limits," Science 269 (1995): 164-169.

6. Robert D. Bullard and G. S. Johnson, "Environmental justice: Grassroots activism and its impact on public policy decision making," Social Issues 56 (2000): 555-78.

7. Julian Agyeman, P. Cole, R.Haluza-DeLay, and P. O'Riley. Speaking for Ourselves: Environmental Justice in Canada. (Vancouver: University of British Columbia Press, 2009).

8. Frederick Engels. The Condition of the Working Class in England. (London: Penguin Classics,1987).

9. Robert D. Bullard. Dumping in Dixie. (Boulder: Westview Press, 3rd ed., 2000).

10. United Church of Christ Commission for Racial Justice. Toxic Waste and Race in the United States: A National Report on the Racial and Socioeconomic Characteristics of Communities with Hazardous Wastes Sites. (New York: United Church of Christ, 1987).

11. United Church of Christ, Toxic Waste andRrace at Twenty: 1987-2007. (New York: United Church of Christ, 2007).

12. Colette R. Palamar, "The justice of ecological restoration: Environmental history, health, ecology, and justice in the United States," Human Ecology Review, 15 (2008): 82-94.

13. Paul Mohai and Robin Saha, "Reassessing social and economic disparities in environmental justice research," Demography 43 (1996): 383-399.

14. Rebecca Morley, "The cost of being poor: Poverty, lead poisoning, and policy implementation," JAMA 295 (2006): 1711-1712.

15. Michael Buzzelli, Michael Jerrett, Richard Burnett, and Norman Finklestein, "Spatiotemporal Perspectives on Air Pollution and Environmental Justice in Hamilton, Canada, 1985-1996," Annals of the Association of American Geographers 93 (2003): 557-73. 
16. Susan L. Cutter and William D. Solecki, "Setting environmental justice in space and place: acute and chronic airborne toxic releases in the Southeastern United States," Urban Geography 17 (1996): 380-99.

17. Michael Heiman, "Race, waste, and class: New perspectives on environmental justice," Antipode 28 (1996): 111-21.

18. Christophe Schwarte and Maria Adebowale. Environmental Justice and Race Equality in the European Union. (London: Capacity Global, 2007).

19. Julian Agyeman and Robert Evans, "'Just sustainability': the emerging discourse of environmental justice in Britain?" The Geographical Journal 170 (2004): 155-164.

20. Andil Gosine and Cheryl Teelucksingh. Environmental Justice and Racism in Canada: An Introduction. (Toronto: Emond Montgomery Publications Ltd., 2008).

21. Laura Pulido, "A critical review of the methodology of environmental racism research," Antipode 28 (1996): 142159.

22. Robert D. Bullard and D.H. Wright, "Environmental justice for all: community perspectives on health and research needs," Toxicology and Industrial Health 9 (1993): $821-4$.

23. William Bowen, "An analytical review of environmental justice research: What do we really know?" Environmental Management 29 (2002): 3-15.

24. Geoffrey Barnes, Jamie Baxter, Andrea Litva, and Brian Staples, "The social and psychological impact of the chemical contamination incident in Weston Village, UK: A qualitative analysis," Social Science \& Medicine 55 (2002): 2227-2241.

25. Susan J. Elliott, Sarah Wakefield, S. Martin Taylor, James R. Dunn, Steven Walter, Aleck Ostry and Clyde Hertzman, "A comparative analysis of the psychosocial impacts of waste disposal facilities," Journal of Environmental Planning and Management 47 (2004): 351-364.

26. Kelvin Jones and Graham Moon. Health, disease, and society: A critical medical geography. (London: Routledge, 2nd ed., 1997).

27. Richard Wilkinson. Unhealthy Societies-The Afflictions of Inequality. (London: Routledge, 1996).

28. Ann Robertson and Meredith Minkler, "The new health promotion movement: A critical examination," Health Education Quarterly 21 (1994): 295-312.

29. Frances Baum. The new public health: An Australian perspective. (Oxford: Oxford University Press, 1998).

30. World Health Organization (WHO). Preamble to the Constitution of the World Health Organization as adopted by the International Health Conference. (New York, 19-22 June, 1946; signed on July 22, 1946 by the representatives of 61 States (Official Records of the World Health Organization, no. 2, p. 100) and entered into force on April 7, 1948).

31. Michael Marmot and Richard Wilkinson (eds.). Social Determinants of Health. (Oxford: Oxford University Press, 2nd ed., 2006).

32. Michael Marmot, "Social determinants of health inequalities," Lancet 365 (2005): 1099-1104.

33. Johan P. Mackenbach and Martijntje J. Bakker, "Tackling socioeconomic inequalities in health: Analysis of European experiences," Lancet 362 (2003): 1409-1414.

34. Nancy E. Adler, Thomas Boyce, Margaret A. Chesney, Sheldon Cohen, Susan Folkman, R.L. Kahn, and S.L.
Syme, "Socio-economic status and health: the challenge of the gradient," in Cacioppo et al. (eds.). Foundations of Social Neuroscience. (Boston: MIT Press, 2002).

35. Angus Deaton and Darren Lubotsky, "Mortality, inequality and race in American cities and states," Social Science and Medicine 56 (2003): 1139-1153.

36. Ichiro Kawachi, Norman Daniels and Dean E. Robinson, "Health disparities by race and class: Why both matter," Health Affairs 24 (2005): 343-352.

37. Arlene T. Geronimus, "Understanding and eliminating racial inequalities in women's health in the United States: the role of the weathering conceptual framework," Journal of the American Medical Women's Association 56 (2001):133-6.

38. Cesar G. Victora, Adam Wagstaff, Joanna Armstrong Schellenberg, Davidson Gwatkin, Mariam Claeson, and Jean-Pierre Habicht, "Applying an equity lens to child health and mortality: more of the same is not enough," Lancet 362 (2003): 233-41.

39. Paula Braveman and Sofia Guskin, "Poverty, equity, human rights and health," Bulletin of the World Health Organization 81 (2003): 540-545.

40. Mary E. Northridge, E. Sclar, and P. Biswas, "Sorting out the connections between the built environment and health: A conceptual framework for navigating pathways and healthy cities," Journal of Urban Health 80 (2003): 556568.

41. Amy Schulz and M.E. Northridge, "Social determinants of health: implications for environmental health promotion," Health Education and Behavior 31 (2004): 455-471.

42. Ken Sexton, and John Adgate, "Looking at environmental justice from an environmental health perspective," Journal of Exposure Analysis and Environmental Epidemiology 9 (1999): 3-8.

43. Philip J Landrigan, Carole A Kimmel, Adolfo Correa, and B. Eskenazi, "Children's health and the environment: Public health issues and challenges for risk assessment," Environmental Health 112 (2004): 257-65.

44. Sylvia Hood Washington, Robert D. Bullard, and K. Olden, "Interview with Robert D. Bullard, Ph.D. and Kenneth Olden, Ph.D., Sc.D., L.H.D," Environmental Justice 3 (2010): 1-6.

45. M. Northridge et al., "Sorting out the connections between the built environment and health," 556-568.

46. Charles Lee, "Environmental justice: Building a unified vision of health and the environment," Environmental Health Perspectives 110 (2002): 141-144.

47. P.J. Landrigan, V.A. Rauh, and M.P. Galvez, "Environmental justice and the health of children," Mount Sinai Journal of Medicine 77 (2010):178-187.

48. R. Morello-Frosch, M. Pastor, and J. Sadd, "Environmental justice and southern California's 'riskscape': The disribution of air toxics exposures and health risks among diverse communities," Urban Affairs Review 6 (2002): 551-578.

49. P. Brown, "Popular epidemiology revisited," Current Sociology 45 (1997): 137-156.

50. Amy Schulz and M.E. Northridge, "Social determinants of health," 455-471.

51. J.A. Terrell, E.M. Williams, C.M. Murekeyisoni, R. Watkins, and L. Tumiel-Berhalter, "The communitydriven approach to environmental exposures: How a 
community-based participatory research program analyzing impacts of environmental exposure on lupus led to a toxic site cleanup," Environmental Justice 1 (2008): 87-92.

52. Gary Taubes and Charles C. Mann, "Epidemiology faces its limits," 164-169.

53. Anthony Gatrell. Geographies of Health: An Introduction (Oxford: Blackwell, 2002).

54. Celia B. Fisher, "Ethics in drug abuse and related HIV research," Applied Developmental Science 8 (2004): 91-103.

55. C. Lee, "Environmental justice: Building a unified vision of health and the environment," 141-144.

56. Nancy Krieger and S. Sidney, "Racial discrimination and blood pressure: the CARDIA study of young black and white adults," American Journal of Public Health 86A (1996): 1370-1378.

57. Gilbert C. Gee, "A multilevel analysis of the relationship between institutional racial discrimination and health status," American Journal of Public Health 92 (2002): 615623.

58. Ronal C. Kessler, Kristen D. Michelson, David R. Williams, "The prevalence, distribution and mental health correlates of perceived discrimination in the United States," Journal of Health and Social Behavior 40 (1999): 208230.

59. Irene H. Yen, David R. Ragland, Birgit A. Greiner, and June M. Fisher, "Workplace discrimination and alcohol consumption: findings from the San Francisco Muni Health and Safety Study," Ethnicity and Disease 9 (1999): 70-80.

60. Richard G. Wilkinson, "Socioeconomic determinants of health: Health inequalities: relative or absolute material standards?" British Medical Journal 314 (1997): 591.

61. Arlene T. Geronimus, "The weathering hypothesis and the health of African-American women and infants: evidence and speculations," Ethnicity and Disease 2 (1992): 207.

62. Arlene T. Geronimus, M Hicken, D Keene, and J Bound, "'Weathering' and age patterns of allostatic load scores among blacks and whites in the United States," American Journal of Public Health 96 (2006): 826-33.

63. Arlene Geronimous et al., "Weathering and age patterns," 826-33.
64. Arlene Geronimus, "Understanding and eliminating racial inequalities in women's health in the United States,"133-6.

65. Mary E. Northridge et al., "Sorting out the connections between the built environment and health," 556-568.

66. A. Schulz and M. Northridge, "Social determinants of health," 455-471.

67. Bruce McEwen, "Stress, adaptation, and disease: allostasis and allostatic load," Annals of the New York Academy of Sciences 840 (1998): 33-44.

68. Miles G. Taylor, "Timing, accumulation, and the black/ white disability gap in later life: A test of weathering," Research on Aging 30 (2008): 226-250.

69. C. Lee, "Environmental justice: Building a unified vision of health and the environment," 141-144.

70. K. Sexton, K. Olden, B.L. Johnson, "'Environmental justice': the central role of research in establishing a credible scientific foundation for informed decision making," Toxicology and Industrial Health 9 (1993): 685-727.

71. Giles C. Gee, Devon C. Payne-Sturges, "Environmental health disparities: a framework integrating psychosocial and environmental concepts," Environmental Health Perspectives 112 (2004): 1645-53.

72. Richard Wilkinson, Unhealthy Societies-The Afflictions of Inequality.

73. Giles C. Gee, Devon C. Payne-Sturges, "Environmental health disparities," 1650.

74. Jeffrey R. Masuda, Tara Zupancic, Blake Poland, and Donald C. Cole, "Environmental health and vulnerable populations in Canada: Mapping an integrated equityfocused research agenda," Canadian Geographer 54 (2008): $427-450$.

Address correspondence to: Sarah E.L. Wakefield

Department of Geography University of Toronto

5th Floor, Sidney Smith Hall 100 St. George St. Toronto, ON M5S $1 A 8$

E-mail: sarah.wakefield@utoronto.ca 